\title{
A PERCEPÇÃO AMBIENTAL ACERCA DO PARQUE ESTADUAL SERRA FURADA EM DOCENTES DE UMA ESCOLA PÚBLICA DE GRÃO-PARÁ
}

\author{
Ney Laine Pickler Gil ${ }^{1}$ e Marcelo D’Aquino Rosa ${ }^{2}$
}

\begin{abstract}
RESUMO
O presente estudo buscou interpretar o modo de conceber o Parque Ambiental Serra Furada, com vistas a estimular a valorização deste ambiente como elemento pedagógico à Educação Ambiental (EA). A pesquisa envolveu seis professores de uma escola municipal de Grão-Pará. Na coleta de dados, empregou-se um questionário e os resultados indicaram que a maioria dos docentes sabia da existência do parque e o considerou um local a ser preservado. Em seu contexto pedagógico, os docentes acreditam que o local pode ser trabalhado por meio de textos, vídeos, filmes, visitas e pesquisas com os moradores do entorno. Além disso, consideram que a EA é um processo em que o indivíduo e o coletivo constroem valores sociais, atitudes e competências para conscientização, sendo este um processo sensibilizador para a incorporação do ser humano ao ambiente. Palavras-chave: Percepção ambiental; Educação ambiental; Unidades de Conservação; Espaços não formais.
\end{abstract}

\section{ABSTRACT}

This study sought to interpret the way of conceiving the Environmental Park Serra Furada, with a view to encouraging the appreciation of this environment as an educational element to the Environmental Education (EE). This research involved six teachers from Grão-Pará municipal school. As data collection instrument, we used a questionnaire and the results indicated that most teachers knew about the park and considered this a site to be preserved. On their pedagogical context, the teachers believed that the park could be worked through texts, videos, movies, visits and surveys with people living around. Also, considered that EE is a process in which the individual and the collective build social values, attitudes and skills to educate and it is emphasized that there should be a sensitizing process of incorporating the humans to the environment.

Keywords: Environmental perception; Environmental education; Protected areas; Non-formal Spaces.

\section{INTRODUÇÃO}

No início do desenvolvimento das sociedades humanas, a civilização buscou e utilizou os recursos que possuía em seu entorno. De acordo com Pedrini e colaboradores (2008), na medida em que estes ficavam escassos, ocorria uma expansão geográfica na busca de novos recursos. Assim que esta relação de uso foi ampliada, o homem mudou seu modo de conceber a natureza e passou a explorá-la de forma intensiva (PEREIRA, 2011).

Gradativamente, a humanidade criou uma postura antropocêntrica, o que causou certo distanciamento em relação à natureza. Esse processo gerou uma crise ambiental que está

\footnotetext{
${ }^{1}$ Licenciada em Ciências Biológicas (UNISUL). Especialista em Ensino de Ciências (IFSC). Professora de Ciências e Biologia da rede pública estadual de Braço do Norte (SC).

${ }^{2}$ Bacharel e Licenciado em Ciências Biológicas (UFSC). Mestre em Educação Científica e Tecnológica (PPGECT - UFSC). Doutorando em Ensino de Ciências e Matemática (PECIM - Unicamp).
} 
refletindo no modelo de sociedade urbano-industrial, composta de seres humanos com valores individualistas e consumistas (GUIMARÃES, 2004).

Em decorrência das perdas do patrimônio natural, há décadas estão sendo criadas áreas naturais conhecidas como unidades de conservação (UC), com a finalidade de estabelecer locais em que a natureza fosse protegida. Conforme a Fundação do Meio Ambiente (FATMA, 2015), as UC são classificadas em: Unidades de Uso Sustentável, na qual pode haver o uso dos recursos naturais - sendo que estas recebem a classificação de reservas de fauna, floresta nacional etc. - e as Unidades de Proteção Integral - em que é permitido o uso indireto dos recursos naturais, sendo que esta categoria é composta por estações ecológicas, reservas biológicas, parques etc.

Esta pesquisa foi realizada no município de Grão-Pará, Santa Catarina, e investigou aspectos referentes ao Parque Estadual Serra Furada (PESF). O parque possui um grande valor em sua biodiversidade, além de ser um belo fragmento de mata atlântica, composto por espécies de plantas e animais que estão ameaçados de extinção, com um significativo recurso hídrico, que integra a bacia do Rio Tubarão, no estado de Santa Catarina.

Conforme as características da área do estudo, consideramos de suma importância que a comunidade do entorno incorpore o parque em sua vida, com o intuito de promover a valorização socioambiental desta região. Contudo, conforme Cerati e Souza (2009), por meio dos estudos de percepção ambiental, é possível compreender a forma como as comunidades percebem as UC, fornecendo, assim, subsídios para a elaboração de estratégias de educação ambiental (EA) e de relações sustentáveis com o entorno.

Há diversas formas de o homem perceber o ambiente. De acordo Pereira (2011) cada pessoa percebe e reconhece o ambiente de forma diferente. "Neste sentido, o modo de perceber o mundo, afeta a forma de atuar do indivíduo sobre o mundo" (BRAGA; MARCOMIN, 2012, p. 159).

Cabe ressaltar que muitas comunidades do entorno de parques ambientais não sabem quais são os objetivos da criação dos mesmos, nem como ocorre o seu funcionamento. Conforme a perspectiva de Nunes (2005) é necessário primeiro conhecer para depois preservar. Nesse sentido, o PESF pode constituir-se num importante lugar a ser utilizado para desenvolver trabalhos em EA. Conforme o Ministério do Meio Ambiente (MMA), os parques podem ser utilizados para visitação, trabalhos em EA e pesquisas científicas.

Os trabalhos em EA podem desenvolver, na comunidade do entorno do parque e nos indivíduos participantes deste processo, a integração do homem com a natureza. Pereira (2011) enfatiza que se faz necessário o desenvolvimento de programas e ações que busquem 
um caráter sensibilizador e que favoreçam uma mudança nos valores e nas atitudes da sociedade. A EA é um processo que deve ser desencadeado com grande ênfase na Educação Básica, já que nela também se dá a formação dos sujeitos - aliás, formação esta que deve se comprometer com o exercício da cidadania.

Desta forma, conhecer a percepção dos professores de uma escola é de suma importância, já que estes são mediadores entre o conhecimento e o educando. Portanto, para isso, o professor deve estar comprometido com o seu papel na formação dos cidadãos para as atuais e futuras gerações, pois, de acordo com Schram e Carvalho (2014), o professor é capaz de coordenar a ação educativa no educando como agente sujeito participante na escola e na vida em sociedade.

A partir deste contexto, a presente pesquisa sustenta-se na seguinte questão: Como o corpodocente daEscola Municipal Professor Gregório Wessler concebe o Parque Estadual Serra Furada, sob o ponto de vista pedagógico e para a comunidade do entorno?

O objetivo norteador desta investigação é verificar a percepção ambiental dos professores acerca do modo de conceber o PESF, com vistas a estimular a valorização deste ambiente como elemento pedagógico propício para um processo de EA não formal. Com este estudo também nos propomos a identificar como os professores concebem a área do PESF como um espaço não formal para as práticas em EA, também em relação às classificações de ambiente de Sauvé (1996; 2005).

\section{PROCEDIMENTOS METODOLÓGICOS}

Esta pesquisa caracteriza-se por ser de cunho qualitativo. Richardson (2011, p. 79-80) salienta este tipo de pesquisa como "a busca por uma compreensão detalhada dos significados e características situacionais dos fenômenos”. Conforme Minayo (2012), o universo humano que corresponde às relações, às representações e à intencionalidade é objeto de pesquisa qualitativa, pois não deve ser transformado em números para ser quantificado.

Esta é uma pesquisa de campo na forma de um estudo de caso, que, segundo Rauen (2002), é uma análise que permite um amplo e detalhado conhecimento, estudando um objeto pelo seu valor intrínseco, valorizando sua unicidade. "O estudo de caso tem como vantagens: o estímulo a novas descobertas, a ênfase na totalidade e a simplicidade dos procedimentos". (RAUEN, 2002, p. 58). Para Bogdan e Biklen (1994), o estudo de caso pode ser representado como um funil, já que, à medida que se conhece melhor o tema de estudo, os planos são modificados e as estratégias são selecionadas. 
O PESF é uma UC de Proteção Integral, criada em 20 de junho de 1980, pelo Governo Estadual de Santa Catarina por meio do Decreto $\mathrm{n}^{\circ} 11.233$, e é regulado pela Fundação do Meio Ambiente de Santa Catarina. Sua área é de 1.330 hectares e abrange os territórios municipais de Orleans e Grão-Pará (Figura 1).

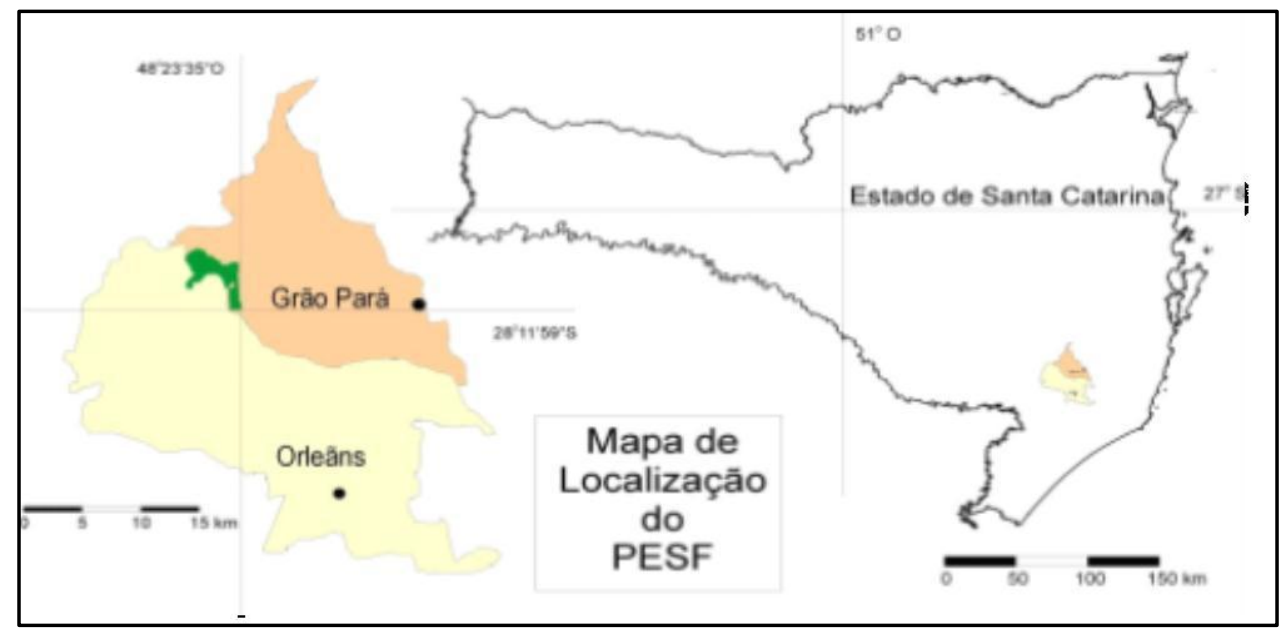

Figura 1- Localização do Parque Estadual da Serra Furada (Fonte: CORDIOLI, 2010).

De acordo com o Sistema Nacional de Unidades de Conservação (SNUC), no parque é permitida a realização de pesquisa científica, práticas de EA e visitação. Logo, para o presente estudo, tal condição favorece que haja, por parte da escola, a integração do parque ao processo educativo nela vivenciado (BRASIL, 1999).

O trabalho foi desenvolvido com professores da escola da rede pública municipal localizada na cidade de Grão Pará, situada a 16 quilômetros do PESF. A definição pela escola se constituiu na primeira etapa deste estudo. Optou-se pela unidade escolar estudada por ser a única escola da rede municipal. A população amostral constituiu-se em seis professores, dos períodos matutino e vespertino. Estes docentes foram codificados com uma letra, entre A e $\mathbf{F}$, concordando em participar desta pesquisa através da assinatura de um Termo de Consentimento Livre Esclarecido (TCLE).

Em razão da viabilidade da escrita de nossa análise, optamos pelo foco em algumas questões do questionário formulado para o estudo. A categorização dos dados foi efetuada mediante a análise de categorias emergentes de Moraes (2007, p. 95), pois, para o autor, “[...] a construção de um conjunto de categorias necessita ser acompanhada da definição e da descrição dos critérios utilizados para incluir elementos dentro de cada categoria". A 
discussão dos resultados englobará os aspectos levantados por Sato (1997), Sauvé (1996; 2005), Carvalho (2006) e outros estudiosos da área de EA.

A concepção de ambiente e natureza foi estudada a partir de uma adaptação das concepções de Sauvé (1996; 2005). A autora estabelece seis concepções sobre ambiente: ambiente como natureza (para ser apreciado, preservado, respeitado), como recurso (paraser gerenciado e uso dos recursos naturais), como problema (que precisa ser resolvido), como um lugar para se viver (conceber, apreender, planejar), como biosfera (onde devemos viver juntos), como projeto comunitário (onde somos envolvidos).

\section{RESULTADOS E DISCUSSÃO}

Em relação ao entendimento que os docentes possuem sobre o que é um parque ambiental, emergiram quatro categorias (Quadro1), sendo que a predominante foi a de "áreas demarcadas para a preservação da fauna e flora usadas para visitação e estudo científicos", com três dos respondentes respondendo por essa opção.

Quadro1. Distribuição de categorias quanto ao entendimento dos docentes sobre parques ambientais

\begin{tabular}{c|c|}
\hline O que você entende por parques ambientais? & $\mathbf{N}^{\mathbf{0}}$ \\
\hline Áreas demarcadas para a preservação da fauna e flora usadas para visitação e estudo científicos. & 3 \\
\hline Áreas destinadas ao turismo e a conservação ambiental. & 1 \\
\hline Reservas de matas com animais e nascentes utilizadas para pesquisa e como um patrimônio \\
natural. & 1 \\
\hline Áreas naturais com características únicas e belezas espetaculares. & 1 \\
\hline Total & $\mathbf{6}$ \\
\hline
\end{tabular}

Conforme o MMA (BRASIL, 2012), se entende por parques as áreas em que é permitida a realização de pesquisas científicas, EA e visitação, não podendo envolver consumo, coleta ou dano aos recursos naturais. Para Sato (2001), deve-se reconhecer que cada pessoa tem uma trajetória de vida, tendo, assim, sua representação, logo, pode se inferir que os professores que elencaram a primeira categoria possuem clareza conceitual acerca do que seja um parque, visto que sua definição atende a definição do MMA. Ao indicarem tal categoria, estes reconhecem a possibilidade desse espaço ser utilizado para visitas e estudos, contudo, não se sabe se de fato o mesmo é incorporado para tal finalidade pela escola e seus professores.

Ainda no que tange ao parque como uma área de preservação utilizada para visitação e estudos, conforme a Lei no 9.985 (BRASIL, 2000), Art. 2º entende-se por "preservação: conjunto de métodos, procedimentos e políticas que visem a proteção a longo prazo das 
espécies, habitats e ecossistemas, além da manutenção dos processos ecológicos, prevenindo a simplificação dos sistemas naturais". Pereira (2011) enfatiza que o termo preservação é considerado como o ato de impedir danos para um recurso.

A segunda categoria, com um respondente, entende parques ambientais como "áreas destinadas ao turismo e conservação ambiental". Contudo pode-se salientar que esta definição é ambígua, pois, de acordo com Art (1998, p.122), define-se conservação como "administração de recursos naturais para fornecer o benefício máximo por um período de tempo estável”.

Na perspectiva de ambiente de Sauvé (1996, 2005), o docente compreende o parque como um recurso para ser usufruído como um atrativo para os turistas, pois considera que, por ser um ponto turístico do município. Convém ressaltar que, se somadas, as duas categorias que consideram a conservação e preservação, estas totalizam quatro docentes, ou seja, o cerne da concepção de parque está ligado à conservação e preservação.

$\mathrm{Na}$ terceira categoria o docente compreende parques ambientais como: "reservas de matas com animais e nascentes utilizadas para pesquisa e como um patrimônio natural.". Ao se verificar a conceituação determinada pelo Instituto Estadual de Florestas do estado de Minas Gerais (2012), por exemplo, vemos que o parque é local de preservação dos ecossistemas naturais de grande relevância ecológica e possibilita a realização de pesquisas científicas, o desenvolvimento de atividades de educação, de recreação em contato com a natureza e de turismo ecológico. Desta forma, verifica-se que este sujeito possui um conceito ambíguo do que é parque, já que tal área não é uma reserva. Para Tassara, Tassara e Mlynarz (2008) reserva é uma UC de proteção integral que possui como objetivo a preservação da biota sem a interferência humana.

Apenas um dos sujeitos questionados dá ênfase aos aspectos e atrativos da natureza. Como os professores foram identificados com códigos em formato de letras do alfabeto, para fins deste estudo, cabe ressaltar o relato feito pelo professor identificado como A nesta categoria, ao referir-se sobre o que considera parque ambiental: "áreas naturais com características únicas e belezas espetaculares".

Ao falarem se sabem ou não da existência do parque ambiental no município de GrãoPará, cinco dos respondentes afirmam que sabiam que o município possuía um parque ambiental. Apenas um não sabia da existência do parque e, destes, ao correlacionar o tempo de atuação na escola, nota-se que o docente identificado como A está atuando há sete anos nesta unidade. Dessa forma, pelo tempo de atuação deste professor na escola, o mesmo revela ter outra visão do entorno da mesma, pois o valor atribuído por ele junto com suas 
experiências vividas faz com que veja o PESF com outra lente, e, assim, não percebendo sua existência. Carvalho (2004, p. 34) ressalta que às vezes, deve-se "trocar as lentes para ver as mesmas paisagens com olhos diferentes".

Em relação à pergunta que questionava se "os alunos sabem da existência de um parque ambiental no município de Grão-Pará", as respostas seguem o mesmo padrão da questão anterior. A maioria dos docentes acredita que os alunos sabem da existência do parque, enquanto apenas o professor identificado com o código $\mathbf{E}$ afirmou que os alunos desconhecem a existência deste local.

Ao compararmos os indivíduos que não sabiam da existência do parque e os que acreditam que os alunos não o conheciam também, verifica-se que não permanece em comum nenhum indivíduo entre os dois grupos. Diante deste contexto, pode-se inferir que, quando se conhece algo que se considera importante para ser incorporado na prática pedagógica, seria de esperar que isso se refletisse em uma ação concreta. No presente trabalho, parece para este professor que a área do parque não constitui o entorno da escola, pois não é percebida na sua dimensão pedagógica; logo, esta área não é incorporada ao processo educativo. E se não é incorporada nas práticas escolares, abre margem para que os alunos também não a conheçam.

Conforme a perspectiva de Vygotsky (1999), o professor é uma figura fundamental em uma escola, pois ele é o elo entre o aluno e o conhecimento. Além disso, percebeu-se que o indivíduo identificado com o código $\mathbf{E}$, que assinalou que os alunos não sabem da existência do parque, atua na escola há 23 anos. Autores como Sá (2005) e Guimarães (2006) alertam para a necessidade de uma relação de pertencimento entre os sujeitos e o ambiente em que se situam. Essa condição é fundamental para o reconhecimento do ambiente e sua incorporação ao processo e vivência pedagógica.

Em relação ao parque no contexto pedagógico dos professores, questiona-se se os docentes acreditam ser "interessante trabalhar aspectos relativos a este parque na escola? Por Quê?’. Emergiram desta questão três categorias (Quadro 2), salientando que todas dizem respeito a uma posição afirmativa. Dentre estas, a categoria que prevaleceu foi a "conhecer o parque e o porquê da existência do parque para assim preservá-lo".

Quadro 2. Compreender o interesse dos docentes de trabalhar aspectos relativos ao PESF na escola

\begin{tabular}{l|l|}
\hline Para você, é interessante trabalhar aspectos relativos a este parque na escola? Por quê? & $\mathbf{N}^{\mathbf{0}}$ \\
\hline Conhecer o parque e o porquê da existência do parque para assim preservá-lo. & 3 \\
\hline Para conscientizar os alunos a preservar o local. & 2 \\
\hline Pelo parque estar no mesmo município da escola e por ser conhecimento sociocultural. & 1 \\
\hline
\end{tabular}


Considerando a perspectiva de Nunes (2005), em que é necessário primeiro conhecer para depois preservar, pode-se afirmar que os docentes possuem discernimento que remete a esta perspectiva. Observou-se, assim, que tal categoria reúne aspectos fundamentais de relevância em ações que visem à EA. Rosso (2007) enfatiza que a EA veio para dar respostas aos problemas ambientais e para preparar as futuras gerações para despertar um cuidado frente aos recursos naturais.

Nesta direção, a Proposta Curricular do estado de Santa Catarina prevê que:

Se a principal função da EA é contribuir para a formação de cidadãos conscientes e críticos, capazes para decidirem e atuarem na realidade socioambiental de um modo comprometido com a vida, com o bem-estar de cada um e da sociedade, esta assume uma ampla dimensão, atingindo praticamente todas as áreas do currículo, podendo ser entendida como um sinônimo do que se entende, hoje, por educação escolar. (SANTA CATARINA, 1998, p. 47).

A segunda categoria compreende dois respondentes, cujo cerne é de conscientização. De acordo Nunes (2005), a conscientização é um ato reflexivo que só a própria pessoa pode realizar. Todo indivíduo, quando começa refletir sobre seu mundo, realiza um exercício de conscientização. No entanto, na concepção de Sauvé (1996, 2005), antes do processo de conscientização é preciso que haja uma etapa de sensibilização.

A última categoria indica a questão "pelo parque estar mesmo município da escola e por ser conhecimento sociocultural", esta afirmação do docente contempla o cuidado ao local em que a escola e o parque estão inseridos. Cabe ressaltar também, que o interesse por trabalhar o PESF, observado em três categorias, com cinco respondentes, remete à preservação e conservação do mesmo.

No que tange aos aspectos relativos ao parque que deveriam ser abordados na escola, destacam-se quatro categorias, sendo que a segunda categoria foi a que prevaleceu: "conscientizar, valorizar, preservar, conservar e estudar o local e sua fauna e flora, promovendo pesquisas com os moradores" (Quadro3).

Quadro3. Os aspectos relativos ao parque que deveriam ser abordados na escola

\begin{tabular}{c|c|}
\hline Quais aspectos relativos ao parque deveriam ser abordados na escola? & $\mathbf{N}^{\mathbf{2}}$ \\
\hline Local com diversidade biológica que somos contemplados. & 1 \\
\hline Conscientizar, valorizar, preservar, conservar, estudar o local e sua fauna e flora, promovendo \\
pesquisas com os moradores. & 3 \\
\hline Proteger as nascentes, derrubada das matas e caçada de animais. & 1 \\
\hline Localização, importância e o objetivo do parque. & 1 \\
\hline Total & $\mathbf{6}$ \\
\hline
\end{tabular}


Vale ressaltar aqui uma reflexão acerca dos termos de preservar e conservar. A preservação conceitua-se como

$\mathrm{O}$ ato de proteger, contra a destruição e qualquer forma de dano ou degradação, um ecossistema, uma área geográfica definida, ou espécies animais e vegetais ameaçadas de extinção [...] difere de conservação por preservar a área de qualquer uso que possa modificar sua estrutura natural original. (LIMA-E-SILVA et al, 1999, p. 187).

O Plano de Manejo do PESF elenca como um ponto forte do parque a biodiversidade da flora preservada e a existência de espécies raras e endêmicas. Tassara, Tassara e Mlynarz (2008, p. 53) enfatizam que "conservação é a ação de conservar plantas, animais e outros seres vivos em suas próprias comunidades ecossistemas naturais”. Entretanto Cerati e Souza (2009) frisam que os processos educativos que envolvem a conservação da biodiversidade necessitam ultrapassar a etapa da sensibilização, realizando processos de co-aprendizagem e co-responsabilidade.

Quanto às demais categorias, cabe uma discussão para aquela que se refere à "local com diversidade biológica que somos contemplados". Nesse caso, é importante destacar que os professores chamam a atenção para o benefício que o parque pode trazer para a sociedade local. Aqui, ressalta a questão do antropocentrismo relatado por Reigota (1995), ou seja, os benefícios à humanidade, ao homem, e não à questão da importância do parque como elemento importante da natureza. Nunes (2005, p. 90) compreende por diversidade biológica a "variedade de organismos vivos que existe nos mais diferentes níveis e ambientes da terra". O indivíduo considera o parque um ambiente com diversidade biológica, por isso, de suma importância conservá-lo.

$\mathrm{Na}$ terceira categoria o respondente afirma que o parque deve ser trabalhado na escola, nos aspectos que tangem "proteger as nascentes, derrubada das matas e caçada de animais". Observa-se que o indivíduo percebe o parque como um problema para ser resolvido, como na concepção de Sauvé (1996). Seria interessante investigar se há, nesse parque, área afetada pelo desmatamento e caça, e se tais áreas encontram-se próximas desta escola.

Quando questionados se é possível trabalhar os aspectos pertinentes ao parque em sua prática pedagógica, emergiram duas categorias, com a dominância da categoria "por meio de textos, vídeos, filmes, visitas e pesquisas com os moradores do entorno, com foco de conscientizar para preservar", que corresponde a cinco respondentes (Quadro4). Percebeu-se que estes docentes que elencam estas possibilidades de trabalhar o PESF na prática 
pedagógica apresentam uma boa e relativa noção de como é possível trabalhar em um parque ambiental, no entanto destaca-se novamente o cerne de preservação, em nossa concepção.

Quadro4. Aspectos pertinentes ao parque trabalhados na prática pedagógica

\begin{tabular}{|c|c|}
\hline $\begin{array}{l}\text { De que forma é possível trabalhar aspectos pertinentes ao parque na sua prática } \\
\text { pedagógica? }\end{array}$ & $\mathbf{N}^{\mathbf{0}}$ \\
\hline $\begin{array}{c}\text { Por meio de textos, vídeos, filmes, visitas e pesquisas com os moradores do entorno, com foco de } \\
\text { conscientizar para preservar. }\end{array}$ & 5 \\
\hline Por meio de passeios, questionários, estudos e visitas ao local. & 1 \\
\hline Total & 6 \\
\hline
\end{tabular}

Sato (1997) ressalta sobre a importância de se realizar trabalhos de campo. A promoção dessas atividades nas áreas próximas às escolas é rica, imediata e os alunos tornam-se muito interessados. Medina e Santos (2008) ressaltam que a educação, no mundo de hoje, necessita de ambientes flexíveis em que os alunos entrem em contato com conceitos e ideias proeminentes para seu presente e futuro, sem a manutenção do "status quo" de uma aprendizagem tradicional.

Quanto aos dados relativos a "o que é meio ambiente", emergiram três categorias (Quadro5), sendo que a predominante foi aquela do "conjunto de coisas vivas e não vivas que nos rodeia", compreendendo quatro professores. Cabe ressaltar que esta definição de meio ambiente remete a uma concepção de natureza, sem indícios das interações sociais, políticas e culturais da sociedade, ou seja, mais "ecológica".

Quadro5. Relativo ao que é meio ambiente para os docentes

\begin{tabular}{c|c|}
\hline O que é meio ambiente? & $\mathbf{N}^{\mathbf{0}}$ \\
\hline Conjunto de coisas vivas e não vivas que nos rodeia. & 4 \\
\hline Relação entre os meios físicos, biológicos e antrópico. & 1 \\
\hline É tudo o que nos rodeia. & 1 \\
\hline Total & $\mathbf{6}$ \\
\hline
\end{tabular}

Esta concepção também foi encontrada em Bergmann e Pedrozo (2007), na definição dos docentes da área das ciências naturais para o meio ambiente. Carvalho (2004) destaca que essa visão naturalizada de ver o mundo, com uma ordem biológica, equilibrada em suas relações ecossistêmicas, pode ser problemática quando a interação homem e natureza é focada, por exemplo.

Reigota (2002, p. 76) enfatiza que se deve compreender o meio ambiente "enquanto interação de configurações sociais, biofísicas, políticas, filosóficas e culturais". O conceito que está em Reigota (2002) remete a um meio ambiente com uma representação social. 
Porém, percebe-se que a maioria dos questionados relaciona o termo meio ambiente com a natureza, mas ainda de forma global, pois consideram apenas o entorno e pouco o ambiente relacionam também com o ser humano.

Conforme Sauvé (1996), o meio ambiente é o conjunto da natureza e cultura, além do que as relações que se tem nesse meio, influência nas atitudes e valores, em que o objetivo da EA é, principalmente, a relação do homem com o meio ambiente. Esta definição emerge pela segunda categoria, "relação entre os meios físicos, biológicos e antrópico", resposta de um professor.

Pode-se considerar uma visão socioambiental relatada por Carvalho (2004, p. 37), que reconhece o meio ambiente não apenas como “[...] sinônimo de natureza intocada, mas como um campo de interações entre a cultura, a sociedade e a base física e biológica dos processos vitais [...]". Considerada também uma abordagem que Sauvé (1996) e Reigota (2002) enfatizam como um ambiente que está representando pelos elementos naturais e as interações sociais, superando a lacuna entre o humano e o natural.

A categoria "tudo o que nos rodeia", opção de um professor, cabe para uma discussão em que a definição levantada compreende por tudo aquilo que se tem ao nosso redor, como os elementos da natureza e as interações sociais. $\mathrm{O}$ sujeito se vê fora do ambiente, colocando o homem no centro e não como um elemento pertencente a tudo.

Para analisar os dados referentes à concepção do parque, foi utilizada a classificação de Sauvé (1996; 2005). Nesta questão, os participantes poderiam assinalar mais de uma alternativa e assim o fizeram. Das sete categorias elencadas (Quadro6), predominaram as categorias, 1, 2, 3 e 6, assinaladas por todos os respondentes.

Quadro6. Concepção do parque pelos docentes, quanto à classificação de Sauvé (1996; 2005)

\begin{tabular}{|c|c|}
\hline Um parque ambiental é importante: & $\mathbf{N}^{\mathbf{0}}$ \\
\hline 1. Como recurso para pesquisa científica. & 6 \\
\hline 2. Como recurso para a Conservação da Natureza. & 6 \\
\hline 3. Como área de visitação para as pessoas. & 6 \\
\hline 4. Como um ambiente com problemas. & 0 \\
\hline 5. Como patrimônio do Planeta. & 5 \\
\hline 6. Como um projeto de importância para a comunidade. & 6 \\
\hline 7. Como recurso para a comunidade de entorno. & 2 \\
\hline
\end{tabular}


Nas categorias 1, 3 e 7 que correspondem ao parque como um recurso, todos os docentes compreendem concordaram com as categorias 1 e 3, enquanto a categoria 7 foi assinalada por apenas dois professores. Conforme Sauvé (2005, p. 317), “[...] não se trata de "gestão do meio ambiente", antes, porém da "gestão" de nossas próprias condutas individuais e coletivas com respeito aos recursos vitais extraídos deste meio".

No que tange à concepção de parque como biosfera, a categoria 5 abrangeu cinco respondentes. A categoria 4 engloba a concepção de parque como problema para resolvido, e isso não ocorreu nesse estudo. A categoria 6 corresponde à compreensão parque como um projeto comunitário, sendo selecionada por seis dos questionados.

\section{CONSIDERAÇÕES FINAIS}

Conforme analisamos, com a ajuda da literatura ao longo do item anterior, cada indivíduo possui determinada percepção sobre ambiente e esta percepção pode ser afetada por suas experiências e o tempo de contato com o referido local.

Ao analisarmos a concepção dos docentes da escola observada neste estudo, quanto ao PESF, observou-se, que cinco dos docentes sabem da existência do parque e afirmam que os alunos também o conheciam. Cabe enfatizar que metade dos docentes possui clareza do que é de fato um parque ambiental, contudo o cerne da concepção de parque está direcionado às questões de conservação e preservação.

Quanto ao parque, no contexto pedagógico, vale ressaltar que para todos os docentes seria interessante trabalhar aspectos relativos ao parque na escola, prevalecendo aqueles relacionados à conservação e preservação deste. Neste contexto pode-se considerar a perspectiva de Nunes (2005) que salienta a necessidade de conhecer para preservar.

Com relação ao meio ambiente, prevalece a concepção do que nos rodeia e as coisas vivas e não vivas, ou seja, uma concepção de natureza sem indícios das interações sociais, políticas e culturais da sociedade, constituindo-se em uma concepção mais "ecológica" ou conservacionista de EA (LAYRARGUES; LIMA, 2011).

Quanto à classificação de Sauvé (1996, 2005), o PESF prevaleceu como recurso para pesquisa científica, conservação da natureza, área de visitação para as pessoas ou um projeto de importância para a comunidade. Todas estas categorias foram assinaladas pelos seis docentes participantes deste estudo, contudo pode-se observar uma concepção generalizada de parque. 
Dada a importância que a área apresenta devido à sua beleza, biodiversidade, patrimônio, entre outras, seria interessante um trabalho junto aos docentes, a fim de enfatizar a relação de pertencimento dos sujeitos em relação ao parque e à comunidade. Os docentes percebem que o ser humano pertence ao meio ambiente, mas consideram o PESF um local que deva ser preservado e conservado sem o ser humano integrar-se completamente a ele, ou seja, não responsabilizando-se de forma integral pelo mesmo.

Avaliamos que seria positivo um processo de formação continuada destes professores para as práticas em EA. Desta forma, estes sujeitos estariam melhor inseridos em um processo que de fato reconheça a relação homem-natureza, rompendo com o distanciamento que existe em relação aos sujeitos, a escola, as práticas educativas não formais e o PESF. Sugerimos por fim que os recursos naturais que o PESF oferece para a comunidade sejam mais bem conhecidos e compreendidos, quer do ponto de vista biológico, como elemento da paisagem ou para o ecossistema local e regional.

\section{REFERÊNCIAS}

ART, H. W. Dicionário de ecologia e ciências ambiental. 6 ed. São Paulo: Companhia Melhoramento, p. 583, 1998.

BERGMANN, M.; PEDROZO, C. S. Percepção ambiental de estudantes e professores no município de Giruá, RS. Rev. Eletrônica Mestrado Educação ambiental, Rio Grande, v. 19, p. 139-156, jul./dez. 2007.

BOGDAN, R.; BIKLEN, S. Características da investigação qualitativa. In: Investigaçãoqualitativa em educação: uma introdução à teoria e aos métodos. Porto: Porto, 1994.BRAGA, R. N.; MARCOMIN, F. E. Percepção ambiental como ferramenta para educação ambiental: uma investigação junto a moradores e veranista do entorno da Lagoa Arroio Corrente- Jaguaruna- Santa Catarina. In: MENDONÇA, A. W.; SIQUEIRA, A. B.; MARCOMIN. F. E. (Org.). Educação, Sociedade e meio ambiente no estado de SantaCatarina: múltiplas abordagens. São Leopoldo: Okos, 2012.

BRASIL. Fundo Mundial da Natureza. WWF. 2012. Disponível em: <http://www.wwf.org.br/natureza_brasileira/questoes_ambientais/biomas/bioma_mata_atl/>. Acesso em: 15 jul. 2013.

Lei $\mathbf{n}^{0}$ 9.795, de 27 de abril de 1999. Lei de Educação Ambiental. Dispõe sobre a educação ambiental, institui a Política Nacional de Educação Ambiental e dá outras providências. Disponível em: <http://www.planalto.gov.br/ccivil_03/leis/19795.htm>. Acesso em: 19 jul. 2013.

Lei n⿳ 9.985, de 18 de julho de 2000. Regulamenta o art. 225, § $1^{\circ}$, incisos I, II, III e VII da Constituição Federal, institui o Sistema Nacional de Unidades de Conservação da Natureza e dá outras providências. Disponível em:

<http://www.planalto.gov.br/ccivil_03/leis/19985.htm>. Acesso em: 20 ago. 2013. 
CARVALHO, I. C. de M. Educação ambiental: a formação do sujeito ecológico. São Paulo: Cortez, 2004.

CARVALHO, V. S. Educação ambiental \& desenvolvimento comunitário. 2. ed. Rio de Janeiro: Wak, 2006.

CERATI, T. M.; SOUZA, A. Q. Educação Ambiental e Percepção: O Caso do Parque Estadual das Fontes do Ipiranga. São Paulo, Brasil. Rev. Eletrônica Mestrado Educaçãoambiental, Rio Grande, v. 23, jul./dez. 2009.

CORDIOLI, S. (Org.). Plano de manejo PESF. Anexo X - Relatório Temático da Oficina de Planejamento Participativa e Análise Estratégica. Florianópolis, 2010.

GUIMARÃES, M. A formação de educadores ambientais. Campinas: Papirus, 2004.

Abordagem Relacional como forma de Ação. In: GUIMARÃES, M. (Org.). Caminhos da Educação Ambiental: da forma à ação. Papirus: Campinas, 2006.LAYRARGUES, P. P.; LIMA, G. F. C. Mapeando as macro-tendências político-pedagógicas da Educação Ambiental contemporânea no Brasil. In: VI Encontro Pesquisa em EducaçãoAmbiental: a pós-graduação.Anais..Ribeirão Preto: USP, 2011.

MEDINA, N. M.; SANTOS, E. C. Educação ambiental: uma metodologia participativa de formação. 4. ed. Petrópolis: Vozes, 2008.

MINAS GERAIS. Instituto Estadual de Florestas. Parque estadual. 2012. Disponível em:

<http://www.ief.mg.gov.br/component/content/114?task=view>. Acesso em: 10 out. 2013.

MINAYO, M. C. S. O desafio da pesquisa social. In: MINAYO, M. C. S.; DESLANDES, S. F.; GOMES,R. Pesquisa social: teoria, método e criatividade. 29. ed. Petrópolis: Vozes, 2012.

MORAES, R. Mergulhos Discursivos: análise textual qualitativa entendida como processo integrado de apender, comunicar e intervir. In: GALLIAZI, M. C.; FREITAS, J. V. (Org.). Metodologias emergentes de pesquisa em educação ambiental. Ijuí: Ed. Unijuí, 2007.

NUNES, E. R. M. Alfabetização Ecológica: um caminho para a sustentabilidade. Porto Alegre: Ed. do Autor, 2005.

PEREIRA, S. M. “GOOGLE EARTH”: a imagem de satélite como ferramenta para aanálise da percepção e para o uso de "expressões de cunho ambiental". Curso de Ciências Biológicas da Unisul - Campus de Tubarão. 2011. Monografia (Graduação emCiências Biológicas)- Universidade do Sul de Santa Catarina, Tubarão, 2011.

RAUEN, F. J. Roteiros de investigação científica. Tubarão: Ed. Unisul, 2002.

REIGOTA, M. Meio ambiente e Representação Social. São Paulo: Cortez, 1995.

. A floresta e a escola: por uma educação ambiental pós-moderna. 2. ed. São Paulo: Cortez, 2002.

RICHARDSON, R. J. Pesquisa Social: métodos e técnicas. 3. ed. São Paulo: Atlas, 2011. ROSSO, A. J. A distância entre o projeto da educação Ambiental e a forma como se efetiva o Ensino de Ciências. In: GUERRA, A. F. S.; TEGLIEBER, J. E. (Orgs.). EducaçãoAmbiental: fundamentos, práticas e Desafios. Itajaí: Universidade do Vale do Itajaí, 2007.SÁ, L. M. Pertencimento. In: JÚNIOR, L. F. (Org.). Encontros e caminhos: formação de educadoras (es) ambientais e coletivos educadores. Brasília: MMA, 2005. 
SANTA CATARINA. Secretaria de Estado da Educação. Proposta Curricular de educação infantil, ensino fundamental e médio (disciplinas curriculares). Florianópolis: COGEN,1998.

SATO, M. Educação para o ambiente amazônico, do Curso de Ciências Biológicas daUniversidade Federal de São Carlos. 1997. Tese (Doutorado em Educação Ambiental)Universidade Federal de São Carlos, São Carlos, 1997.

Debatendo os desafios da Educação Ambiental. Rev. Eletrônica MestradoEducação Ambiental, Rio Grande, v. 1, p. 14-33, 2001.

SAUVÉ, L. Environmental Education and Sustainable Development: A Further Appraisal. In: Canadian Journal of Environmental Education, v. 1, n. 1, p. 7-34, 1996.

. Uma cartografia das correntes em educação ambiental. In: SATO, M.; CARVALHO, I. C. M. (Orgs.). Educação Ambiental: pesquisas e desafios. Porto Alegre: Artmed, 2005.

SCHRAM, S. C.; CARVAlho, M. A. B. O Pensar Educação em Paulo Freire: para uma Pedagogia de mudanças. Disponível em: <http://www.diaadiaeducacao.pr.gov.br/portals/pde/arquivos/852-2.pdf>. Acesso em: 24 ago.2014.

TASSARA, E. T. O.; TASSARA, H.; MLYNARZ, R. B.. Dicionário Socioambiental: Idéias, Definições e Conceitos. São Paulo: FAARTE, 2008.

TILBURY, D. Environmental education for sustainability: defining the new focus of environmental Education in the 1990s. EnvirommEducation, v. 1, n. 2, p. 195-212, 1995. 